Gazi University
Journal of Science
http://dergipark.gov.tr/gujs

\title{
Modeling Rheological Behavior of Beef based on Time-Dependent Deformation and Packaging
}

\author{
Adeshina FADEYIBI* \\ Highlights \\ - Rheological properties of packaged beef were studied for different processes. \\ - Shear stress increases with the percent rate of shear. \\ - Deformation index varies in the range of $1<\mathrm{n}<3$. \\ - A non-Newtonian shear thickening behavior was established. \\ - Tiu-Boger theory gave a better k estimate for A. Foil at $5^{\circ} \mathrm{C}$.
}

Department of Food and Agricultural Engineering, Kwara State University, Malete, P.M.B. 1530, Ilorin, Kwara State, Nigeria

\begin{tabular}{l} 
Article Info \\
\hline \\
Received: 24 May 2020 \\
Accepted: 10 Aug 2021 \\
Keywords \\
Shear stress \\
Yield stress \\
Modeling \\
Packaging \\
Beef
\end{tabular}

\begin{abstract}
Modeling of food deformation behavior is vital for structural characterization. This research was undertaken to study the rheological properties of beef by developing mathematical models for different packaging and temperature conditions. The rheological properties of the beef sample, packaged in a polyethylene (LD and HD) and aluminum foil (A foil), were determined experimentally at $-20^{\circ} \mathrm{C}$ and $5^{\circ} \mathrm{C}$ for $0-60$ days. Power law, Herschel-Bulkley and Tiu-Boger theories, formulated for a period-dependent deformation, were used to constitute the models. Results show that the deformation index varies in the range of $1<n<3$, indicating a nonNewtonian shear thickening behavior. Also, a better estimation of the deformation consistency, $k$ was obtained using the Tiu-Boger theory for the A. Foil at $5^{\circ} \mathrm{C}$ and Herschel-Bulkley theory for the $\mathrm{LD}$ at $-20^{\circ} \mathrm{C}$. The models are significant with MSE $<5 \%$ and $\mathrm{R}^{2}>85 \%$, suggesting their suitability for industrial scale-up prediction.
\end{abstract}

\section{INTRODUCTION}

The production capacity of livestock products, in the food industry is closely related to population growth, rising incomes, and urbanization. It has been estimated that there will be two-thirds increase in the world consumption rate of beef alone by the year 2050 [1,2]. Thus, the livestock sector will grow and transform, resulting in new relationships between domestic animals and the populations with a serious consequence on the food sector [1]. Assessing the impact of the current livestock on the food sector is thus critical to the understanding of how the growth and transformation of this sector can impact society, and to identify actions to take to ensure sustainable development of the product.

Domestication of cattle for beef, milk and leather production is essential for food processing. The knowledge of the quality of beef, which includes the nutritional composition, organoleptic characteristics, and rheological properties, is essential in determining its success of preservation in the food industry. The major purpose of preserving beef products is to extend the keeping quality beyond its normal shelf-life [1]. To achieve this, freezing and cooling have been used as the two most common beef preservation approaches [2]. The freezing of fresh beef can be done by keeping it below $-10^{\circ} \mathrm{C}$ temperature and above $80 \%$ relative humidity, whereas the temperature of cooling is in the range of $0-10^{\circ} \mathrm{C}$. Packaging is another method of prolonging the shelf-life of beef. This is primarily done to protect the beef during the distribution process and contamination by dirt, micro-organisms, moulds, yeasts, parasites, or toxic substances. However, there is always a possibility of tempering with the food structure at these preservation temperatures even when ideal packaging is employed [1]. For instance, the beef might lose its rheological nature and tenderness thereby affecting its acceptability and the overall industrial application [3]. The potential tenderness of beef 
maybe judged based on the type of muscle and the grade of the carcass. These criteria are indications of the commercial value and the manner of processing the beef [4]. Therefore, qualitative analysis of the beef rheological behavior is usually needed throughout a storage period to ensure that a healthy product is made available at any time of demand.

It is essential to find a reliable means of accurately assessing the beef tenderness and rheological properties. The measurement of the rheological properties of food under the same laboratory conditions, is usually inconsistent to describe [2,5]. The nature of the food under test, method of sample preparation and time often interfere with the measurement accuracy. Thus, to address this challenge, mathematical modeling of the rheological properties of food under various degree of applied loads have been suggested to give meaningful insights to the problems in the industry [1,6-9]. Unlike in the previous investigations where sophisticated equipment like the vane [10], slotted plate [6], cylindrical penetration techniques and so on [11], were described for measuring the rheological behavior of food, we used here a tensometric analyzer to determine the shear stress and percent rate of shear of the beef. Although a mathematical model has been described for mass and heat transfer prediction of meat [12], a major weakness is in its application for predicting the rheological behavior of the beef at cooling and freezing temperatures. Moreover, the study on the effect of packaging materials, temperature and storage period on the shear stress and percent rate of shear of packaged beef have not been reported hitherto. Therefore, the objective of this research was to develop mathematical models for predicting and validating the measured tensile shear stress and rate properties of the beef under various categories of packaging material, storage period and temperature.

\section{MATERIALS AND METHODS}

\subsection{Sample Collection and Preparation}

A $5 \mathrm{~kg}$ of M. semimembranosus cow muscle, which contains $15.5 \%$ protein, $4.3 \%$ fat, $1.7 \%$ ash, and 78.5 $\%$ moisture, was commercially purchased from Quarantined Ipata Market in Ilorin, Kwara state, Nigeria. The beef was wrapped in a Ziploc bag and placed in a locally fabricated iced box, which will help maintain its freshness for the period of analysis. The box was immediately transported to the Diagnostic Central Laboratory in Ilorin where the laboratory analysis was carried out. Separable fats and connective tissues were removed from the beef before it was cut into pieces of $25 \mathrm{~mm}$ width and $15 \mathrm{~mm}$ thickness for subsequent experimentation.

\subsection{Packaging of the Product}

The samples were divided into three portions; and wrapped and sealed using three types of packages of different material properties, namely low-density polyethylene (LD), high density polyethylene (HD) and Aluminum foil (A foil). The LD has a thickness of $100 \mu \mathrm{m}$, oxygen permeability of $6.4 \mathrm{~m}^{3} / \mathrm{m}^{2}$ Paday at $23^{\circ} \mathrm{C}$. The HD has a thickness of $60 \mathrm{~mm}$, oxygen permeability of $3.7 \mathrm{~m}^{3} / \mathrm{m}^{2} \mathrm{~Pa}$ day at $25^{\circ} \mathrm{C}$ and relative humidity of $60 \%$. The A foil has a thickness of $0.0065 \mathrm{~mm}, 2.7$ specific gravity, melting temperature of $660^{\circ} \mathrm{C}$ and $234 \mathrm{~W} / \mathrm{m} . \mathrm{K}$ thermal conductivity. The sealing was done using single chamber minidual thermal sealing equipment (Model: Schkolnick SAIC, Buenos Aires, $0.6 \mathrm{kPa}$ sealing pressure).

\subsection{Cooling and Freezing of the Product}

A Polystar refrigerator (Model: BCH-40, 5 $8^{\circ} \mathrm{C}$ temperature range, $65 \mathrm{~W}$ power source, China) and an LG freezer (Model: CE/ISO9001, $-150 \sim-20^{\circ} \mathrm{C}$ temperature range, 380V/50HZ Voltage, China) were used respectively as cooling and freezing compartments in this investigation. The samples of the beef from each of the $\mathrm{LD}, \mathrm{HD}$ and $\mathrm{A}$ foil were stored at the $5^{\circ} \mathrm{C}$ cooling and $-20^{\circ} \mathrm{C}$ freezing temperatures for 60 days, at an interval of 10 days. This gives 6 samples from each packaging material. Thus, a total of 18 samples were used for the rheological property analysis.

\subsection{Determination of Rheological Properties}

A Testometric material testing machine (CMT series, ASTM ISO EN JS standard, China) was used to determine the rheological properties of the packaged beef. The machine has a pretension of $0.1 \mathrm{kN}$ at a test 
speed of $5.0 \mathrm{~mm} / \mathrm{min}$. Each of the 18 samples of the packaged beef was subjected to analysis, and the values of the stress (peak and yield) and strain were obtained. The procedure was replicated 3 times for each sample, and the average values and the standard deviation were computed. The values of the tensile stress at peak and the tensile stress at yield were recorded as the shear stress and the yield stress of the product. It is important to note that while shear strain implies an irreversible plastic deformation, the percent rate of shear is the irreversible viscous deformation. Theoretically, we can explain this behavior by considering the deformation of a beef element, relative to some previous state, as a first order strain tensor that changes with time and a time derivative of the element can be likened to the shear rate. Thus, using dimensional analysis, we modified and establish a relationship between the shear strain and the percent rate of shear as shown in Equation (1). Based on this, we applied deterministic theories and obtained parameters to describe the rheological properties of the beef under experimental conditions. The theories were governed by the expression in Equation (2) [13].

$\dot{\gamma}=\frac{\delta_{o}-\delta_{t}}{\delta_{o}} \times 100 \%$

$\tau=\eta \dot{\gamma}$

$$
\tau \propto \dot{\gamma}
$$

where,

$\eta=$ dynamic viscosity, which relate to the elastic modulus of the beef,

$\tau=$ shear stress $(\mathrm{kPa})$,

$\delta_{\mathrm{o}}=$ plastic deformation or shear strain of beef at $t=0(\mathrm{~mm})$

$\delta_{\mathrm{t}}=$ plastic deformation or shear strain of beef at $t=\mathrm{t}(\mathrm{mm})$

$\dot{\gamma}=$ relative percentage rate of beef $(\%)$

\subsection{Mathematical Model for Beef Packaging}

Herschel-Bulkley theory: According to the principle of solid food mechanics, many food products, which include beef can deform under dynamic or repeated loading. The deformation of the product is better understood from the existing relationship among the yield stress, shear stress and shear rate. Theoretically, the product will flow if the applied shear stress exceeds the yield stress. A Herschel-Bulkley theory was therefore used to predict the shear stress versus percent rate of the shear relationship of the beef product under dynamic loading at different storage and packaging conditions, as expressed in Equations (3) and (4).

$\tau=\tau_{y}+K \dot{\gamma}^{n}$

$$
\begin{gathered}
\tau-\tau_{y}=K \dot{\gamma}^{n} \\
\log \left(\tau-\tau_{y}\right)=\operatorname{Iog}\left(K \dot{\gamma}^{n}\right) \\
\log \left(\tau-\tau_{y}\right)=\operatorname{Iog} K+\operatorname{Iog} \dot{\gamma}^{n}
\end{gathered}
$$

$\operatorname{Iog}\left(\tau-\tau_{\mathrm{y}}\right)=\operatorname{Iog} \mathrm{K}+\mathrm{n} \operatorname{Iog} \dot{\gamma}$

where,

$$
\begin{aligned}
& n=\text { deformation behavior index } \\
& K=\text { product consistency index }
\end{aligned}
$$


Power theory: The simplest form of the Herschel-Bulkley theory, called the power theory where there is no yield term, is expressed in Equation (5). The shear stress, shear strain and yield stress data obtained from the shear rheological analysis of the beef were fitted into the power model expressed in Equation $(6)[5,13]$.

$$
\tau=\mathrm{K} \dot{\gamma}^{\mathrm{n}}
$$

$\log \tau=\operatorname{Iog} K+\operatorname{Iog} \dot{\gamma}^{\mathrm{n}}$

$\log \tau=\operatorname{Iog} \mathrm{K}+\mathrm{n} \operatorname{Iog} \dot{\gamma}$

Tiu-Boger theory: Since the rheological properties were obtained as a function of the storage period from 0-60 days, the effect of the properties on material structure needs to be accounted. A period-dependent behavior of shear deformation of the beef was determined using the Tiu- Boger theory expressed in Equation (7). To do this, the data were fitted into the expression and its parameters were obtained. An additional rate equation was used to describe the change of the material structure to the period of storage.

$\tau=\omega\left[\tau_{y}+K \dot{\gamma}^{n}\right]$

where,

$\omega=$ structural parameter whose value depends on the period of the beef storage. For zero shear rate, the structural parameter takes value in the range $\omega_{\mathrm{a}}<\omega<1$. Where $\omega_{\mathrm{a}}$ is the equilibrium parameter at any given period.

A second order kinetic equation was assumed to describe the decay of the structural parameter with the storage period, as expressed in Equation (8). For the shear period, $0<t \leq 60$ days, rate constant, $\mathrm{k}_{1}$, which is a function of the percent rate of shear was determined experimentally. The complete period-dependent rheological characterization of the beef product was described by Equation (9) with the parameters $\tau_{y}, K$, $\mathrm{n}, \mathrm{k}_{1}(\dot{\gamma})$ and $\omega_{a}$.

$$
\begin{array}{ll}
\frac{d \omega}{d t}=-k_{1}\left(\omega-\omega_{a}\right)^{2} & \text { for } \quad \omega>\omega_{a} \\
& \int_{0}^{\omega} \frac{d \omega}{\left(\omega-\omega_{a}\right)^{2}}=-k_{1} \int_{0}^{60} d t
\end{array}
$$

$\frac{1}{\left(\omega-\omega_{a}\right)}=60 k_{1}$

We assumed $\omega_{a}=0.5$ and $k_{1}=1$, thus

$$
\omega=0.517
$$

Therefore, from Equation (7), Tiu-Boger model is expressed in Equation (10).

$$
\begin{aligned}
\frac{\tau}{0.517}-\tau_{y} & =K \dot{\gamma}^{n} \\
\log \left(\frac{\tau}{0.517}-\tau_{y}\right) & =\log \left(K \dot{\gamma}^{n}\right)
\end{aligned}
$$$$
\log \left(1.9 \tau-\tau_{y}\right)=\log K+\log \dot{\gamma}^{n}
$$

Model parameter estimation: All the model parameters were estimated experimentally. The data obtained from the shear stress, percent rate of shear and yield stress analysis of the packaged beef was fitted into the Herschel-Bulkley, Power and Tiu-Boger theories. A $\log -\log$ plot of $\tau-\tau_{y}$ versus $\dot{\gamma}$ was used to obtained $n$ and $K$ parameters in the Herschel-Bulkley theory as the slope and intercept of the resulting straight line, respectively. Similarly, a $\log -\log$ plot of $\tau$ versus $\dot{\gamma}$ was used to the corresponding parameters using the 
power theory. We evaluated the values of the parameters for the Tiu-Boger model from a log-log graph of $1.9 \tau-\tau_{y}$ vs $\dot{\gamma}$. Here again, the parameters $K$ and $n$ were obtained from the slope and intercept of the resulting straight line of the plot, $\tau_{y}$ was obtained from the plot at the point where the percent rate of shear is zero.

Model Validation: The models were validated by evaluating their performances using the different statistical indices namely, the mean square error (MSE), $\mathrm{R}^{2}$ adj. and $\mathrm{R}^{2}$, as expressed in Equation (11) to Equation (13). These statistics allow for the detection of differences between experimental and model predicted data $[14,15]$.

$$
\begin{aligned}
& M S E=\frac{1}{n} \sum_{i=1}^{n}\left(Y-Y_{i}\right)^{2} \\
& R^{2}=\frac{\sum_{i=1}^{n}(\hat{Y}-\bar{Y})^{2}}{\sum_{i=1}^{n}(Y-\bar{Y})^{2}} \\
& R_{\text {adj }}^{2}=1-\frac{\left(1-R^{2}\right)(n-1)}{n-p-1}
\end{aligned}
$$

where,

$$
\begin{aligned}
& Y=\text { response from the experiment } \\
& \hat{Y}=\text { model estimated response } \\
& \bar{Y}=\text { mean response } \\
& \mathrm{n}=\text { sample size } \\
& \mathrm{p}=\text { number of model predictor }
\end{aligned}
$$

\section{RESULTS AND DISCUSSION}

\subsection{Effect of Packaging Materials on Period-Dependent Rheological Properties of Beef}

The rheological properties of the packaged beef are represented in terms of the relationship among the shear stress, shear strain, storage period and temperature, as shown in Figure 1 and Figure 2. The shear stress increases while the shear strain slightly decreases with an increase in the packaging period, irrespective of the category of packaging and storage temperature. This is not surprising, since temperature effects were found to be insignificant and that, for any given package type, the contribution of temperature effect was minimal. This trend is closely related to previous studies [16] and was also observed experimentally [17]. The shear and yield stresses are a function of the beef structure and hence of time. The choice of the observation time is related to the characteristics time of the flow process to which the material is applied. The observed effect may relate to the occurrence of an irreversible deformation resulting from an increase in the yield stress and the attended dislocation at the atomic level. While we acknowledge the multiplex nature of the rheological behavior of the beef under dynamic loading, we try to elucidate the observation as follows. An increase in the stiffness of the beef internal structure under cold and freezing environment is likely responsible for the decreasing shear strain and increasing shear stress with an increase in the storage period and temperature conditions. We wish to point to the fact that the higher the stiffness, the higher the shear stress and the lower the shear strain of the beef samples in storage. The research findings of Jakobsson and Bengtsson [18], Law et al. [19] and Smith et al. [20] corroborate this in their work on the effect of freezing rate and reconstitution method on the quality and yield of beef. Bouton et al. [21] attributed the effects of the shear and yield stress to the resistance offered by the connective tissue of the beef. Also, Locker [22] reported that the beef deformation will increase in stepwise with an increase in the yield stress. Under these conditions, the beef will eventually approach a point of failure, and by implication reduced tenderness and commercial values. 


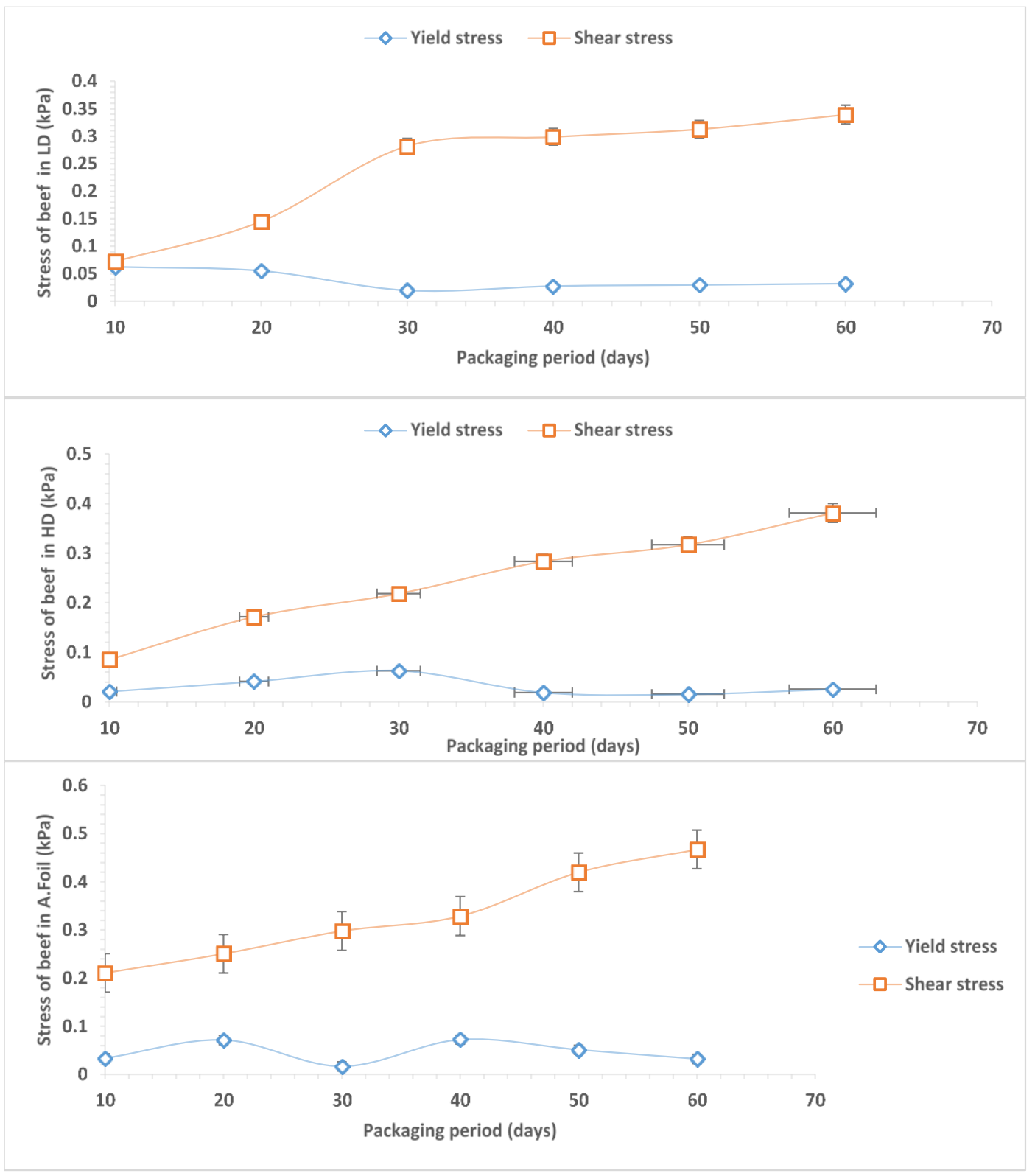

Figure 1. Effect of packaging material and period on beef stress at freezing $\left(-20^{\circ} \mathrm{C}\right)$ 


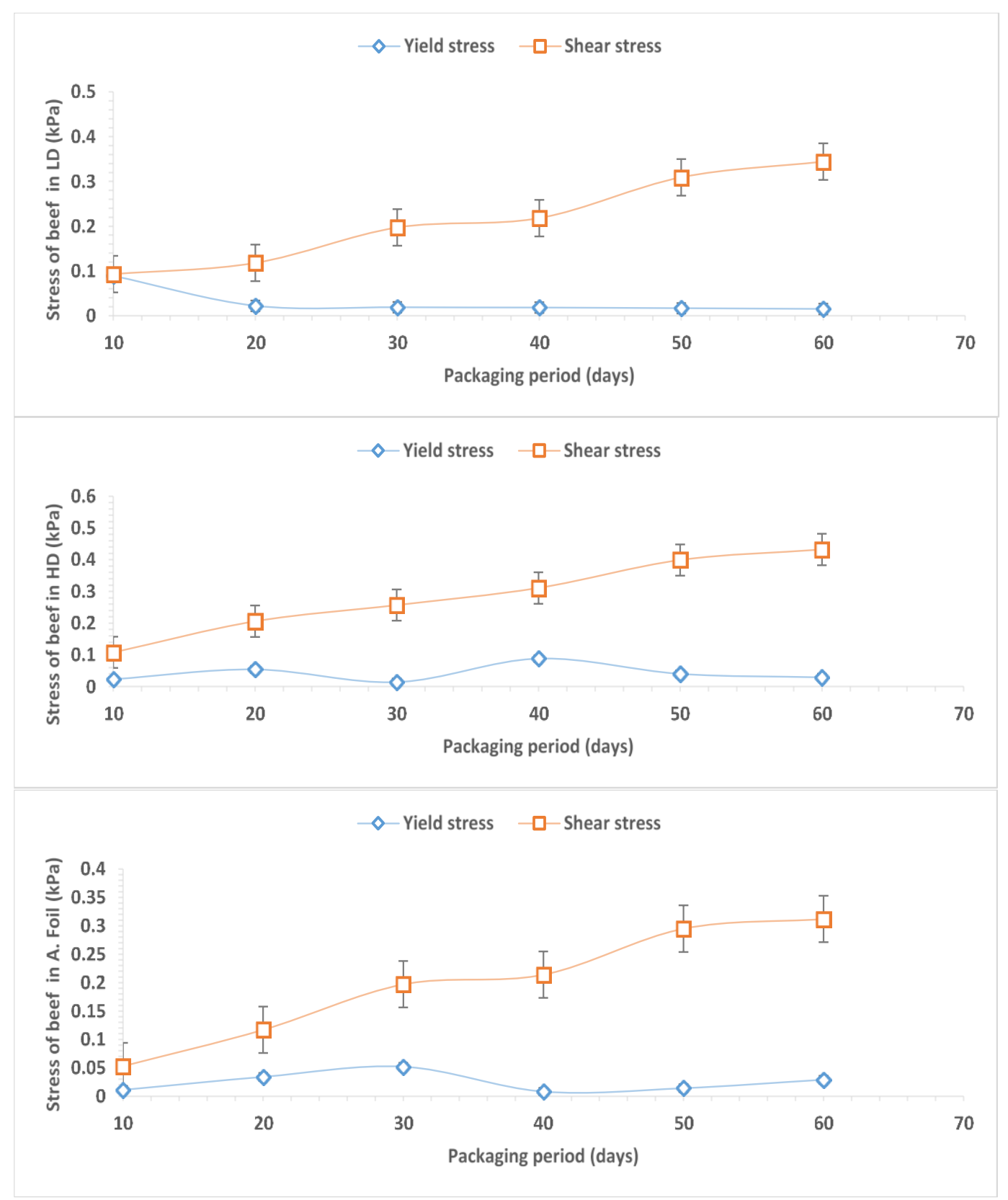

Figure 2. Effect of packaging material and period on beef stress at cooling $\left(5^{\circ} \mathrm{C}\right)$

\subsection{Predicting the Rheological Behavior of Packaged Beef}

Shear strain can be regarded as the change in the deformation of a material caused by the shear stress acting at right angle. The relationships between the shear stress and the percent rate of shear of the packaged beef in the LD, HD and A. Foil packaging materials are shown in Figures 3-5. Also, the result of the independent model validation is presented in Table 1. A general log increase in the shear stress was observed with an increase in the percent rate of shear for all the categories of packaging and temperature with higher coefficients of determination $\left(\mathrm{R}^{2}\right.$ and $\mathrm{R}^{2}$ adj $>80 \%$ ). In other words, a high force may likely cause the beef material to yield with an increase in the deformation rate during storage in the direction of the percent rate of shear. Thus, the shear stress is likely to increase in the beef elements with an increase in the percent rate of shear. This supports the findings of Karaman et al. [15] for meat emulsions in their work on the steady shear rheological characterization of the product. Also, similar rheological behavior was reported by Barbosa et al. [9] for chocolate paste, Chen et al. [23] for bologna sausage and Chapwanya and Misra [12] 
for meat cooking based on polymer solvent analogy. Thus, this behavior may mean a likely dilation of the beef elements in the direction of the percent rate of shear for all categories of packaging and temperature.

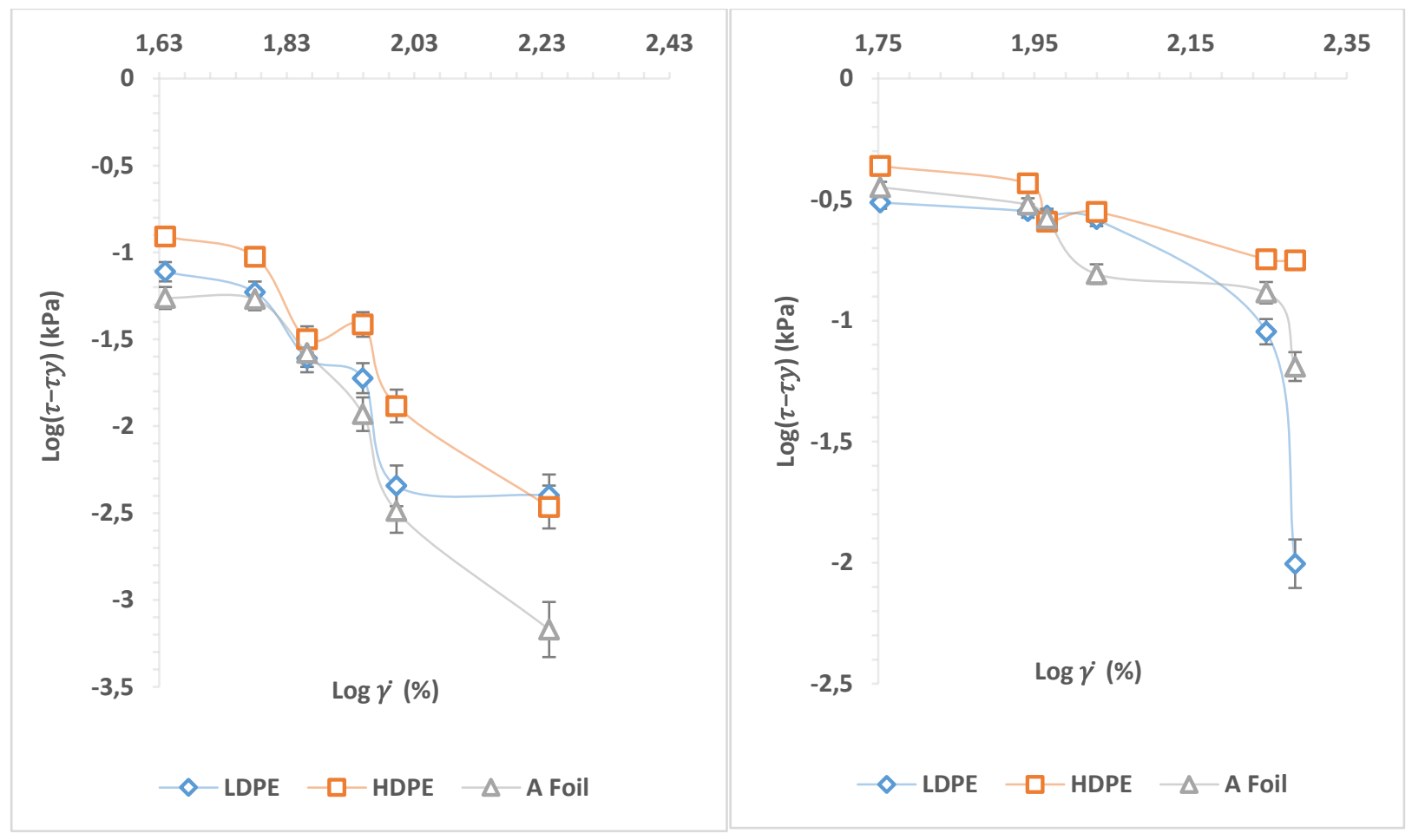

Figure 3. Herschel-Bulkley share stress and percent rate of the shear relationship of packaged beef

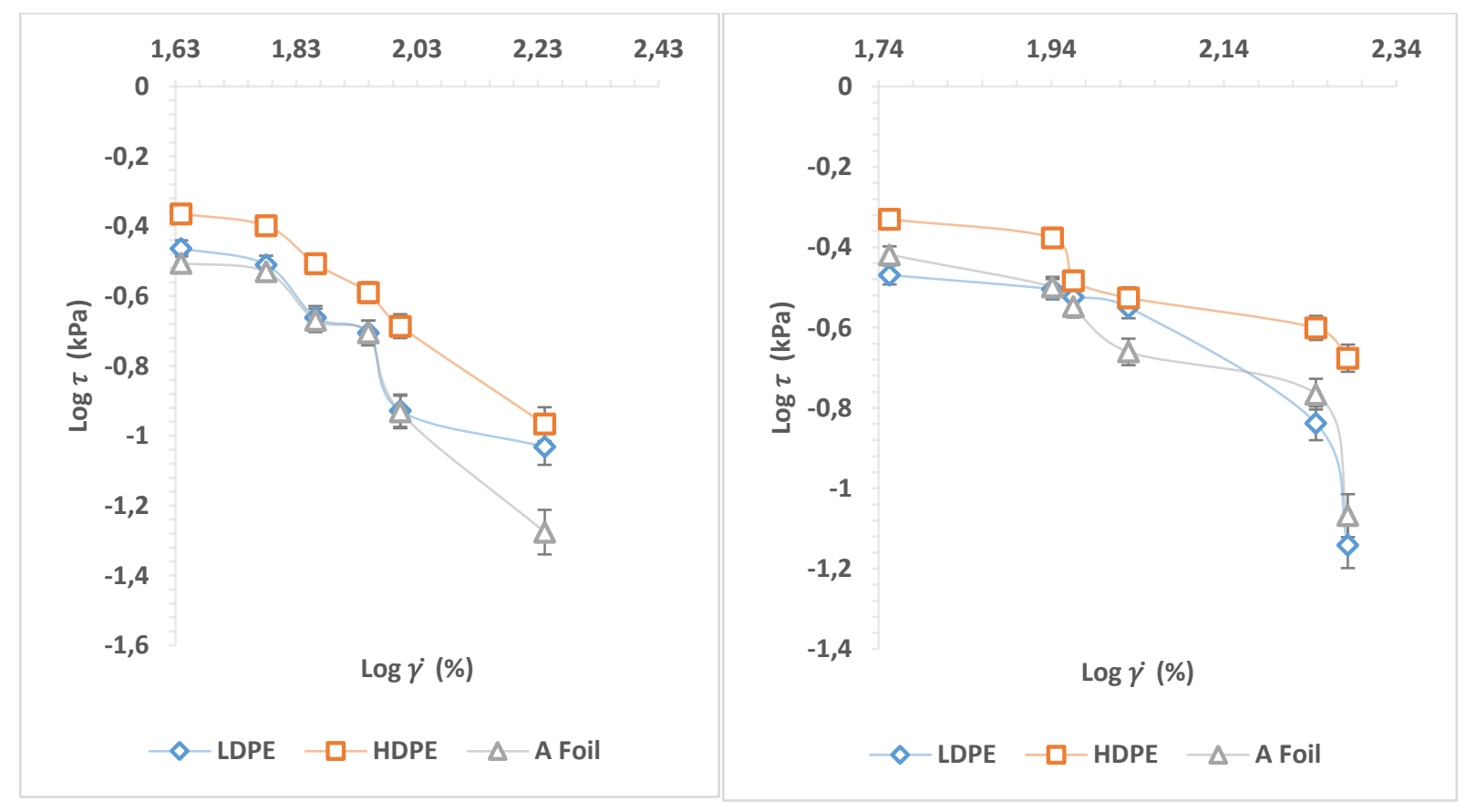

Figure 4. Power share stress and percent rate of the shear relationship of packaged beef 


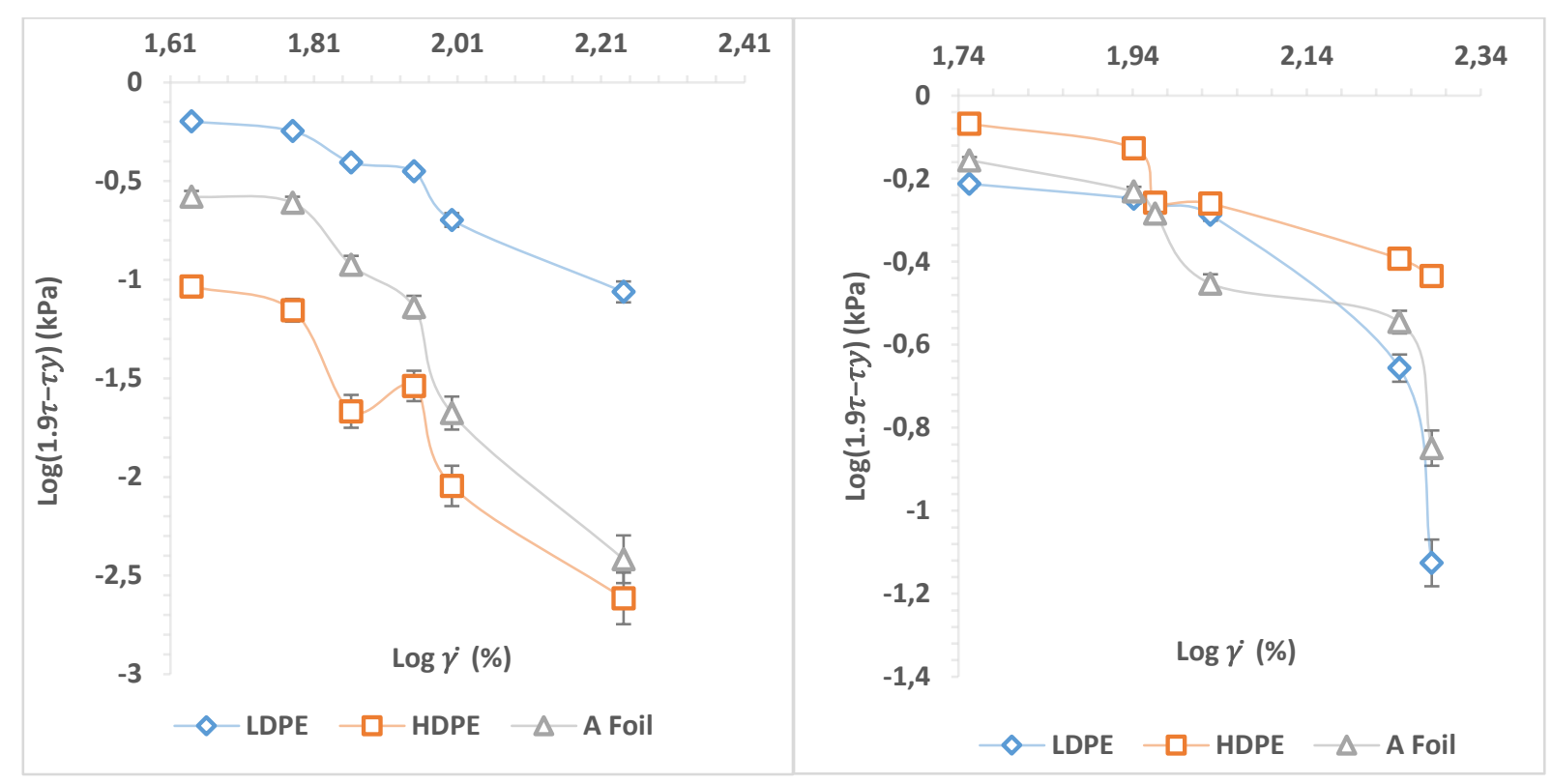

Figure 5. Tiu-Boger share stress and percent rate of the shear relationship of packaged beef

Table 1. Independent model validation for predicting rheological properties

\begin{tabular}{lllllllllll}
\hline & Model & \multicolumn{3}{c}{ Herschel-Bulkley } & \multicolumn{4}{c}{ Tiu-Boger } & \multicolumn{3}{c}{ Power } \\
\cline { 2 - 11 } Temp. & Fitness & LD & HD & A Foil & LD & HD & A Foil & LD & HD & A Foil \\
\hline $5^{\circ} \mathrm{C}$ & $\mathrm{R}^{2}$ & 0.853 & 0.935 & 0.918 & 0.936 & 0.926 & 0.923 & 0.910 & 0.960 & 0.919 \\
& $\mathrm{R}^{2}{ }_{\text {adj }}$ & 0.816 & 0.919 & 0.898 & 0.920 & 0.908 & 0.904 & 0.887 & 0.951 & 0.899 \\
& MSE & 0.036 & 0.018 & 0.039 & 0.007 & 0.021 & 0.180 & 0.004 & 0.002 & 0.006 \\
\hline$-20{ }^{\circ} \mathrm{C}$ & $\mathrm{R}^{2}$ & 0.649 & 0.847 & 0.919 & 0.739 & 0.933 & 0.849 & 0.785 & 0.917 & 0.841 \\
& $\mathrm{R}^{2}{ }_{\text {adj }}$ & 0.561 & 0.809 & 0.899 & 0.674 & 0.917 & 0.811 & 0.732 & 0.896 & 0.801 \\
& MSE & 0.010 & 0.038 & 0.046 & 0.028 & 0.001 & 0.008 & 0.013 & 0.001 & 0.007 \\
\hline
\end{tabular}

The model parameters used for predicting the rheological behavior of the beef based on time-dependent deformation for different packaging materials at cooling $\left(5^{\circ} \mathrm{C}\right)$ and freezing $\left(-20^{\circ} \mathrm{C}\right)$ temperatures were shown in Table 2. A flow behavior index (n) ranging from $1<\mathrm{n}<3$ was generally obtained for all the models, thus indicating a non-Newtonian shear thickening behavior for the packaged beef under different packaging and temperature conditions. The observed behavior may not be unconnected with the tendency of the applied force to disturb the long chain from their favored equilibrium configuration, thereby causing an increase in the shear stress with an increase in the deformation in the direction of the percent rate of shear [14]. The research efforts of Constenla et al. [24], Hassan and Hobani [25], Onwude et al. [26] and Rao and Tattiyakul [16] corroborate our finding in their separate investigations. In another related study, Saraiva et al. [17] reported a similar non-Newtonian behavior for meat stored under vacuum and aerobic packaging conditions. The values of $k$ in the models indicate deformation consistency, and this may imply a change in the percent rate of shear experienced by the beef due to an increase in the applied load. A lower $k$ value indicates that the beef product deforms with an increase in the yield stress of the system, and this depends on the type of packaging. The value of $k$ is higher for the LD model estimator than the other models for the beef stored under frozen conditions. The A. Foil model however is a better estimator of $k$ value for the beef stored under a cooling atmosphere. 
Table 2. Model parameters estimation for predicting rheological properties

\begin{tabular}{lllllr}
\hline \multirow{2}{*}{ Model } & \multicolumn{2}{c}{$5^{\circ} \mathrm{C}$} & \multicolumn{2}{c}{$-20^{\circ} \mathrm{C}$} \\
\cline { 2 - 6 } Herschel-Bulkley & Packaging & $\log \mathrm{K}$ & $\mathrm{n}(-)$ & $\log \mathrm{K}$ & $\mathrm{n}(-)$ \\
\hline \multirow{3}{*}{ Tiu-Boger } & LD & 2.913 & 2.431 & 3.943 & 2.366 \\
& HD & 3.632 & 2.701 & 1.870 & 1.281 \\
& A Foil & 4.769 & 3.514 & 0.983 & 0.764 \\
Power & LD & 2.390 & 1.517 & 2.703 & 1.556 \\
& HD & 3.567 & 2.742 & 1.155 & 0.693 \\
& A Foil & 5.107 & 3.111 & 1.972 & 1.174 \\
& LD & 1.279 & 1.044 & 1.730 & 1.179 \\
& HD & 1.429 & 1.054 & 0.780 & 0.628 \\
& A Foil & 1.821 & 1.354 & 1.528 & 1.074 \\
\hline
\end{tabular}

\section{CONCLUSIONS}

The rheological properties of beef were studied by developing mathematical models for predicting the shear stress and rate for different packaging and temperature conditions. The shear stress increases with the storage period; and decreases with the percent rate of shear or shear strain for all category of packaging and temperature. An increase in the stiffness of the beef internal structure under cold and freezing environment is likely responsible for the decreasing shear strain and increasing shear stress with an increase in the storage period and temperature conditions. In other words, the high stiffness resulting from the low temperature storage of the beef samples can be responsible for the increase in the shear stress and the decrease in the shear strain with increasing period of storage. A non-Newtonian shear thickening behavior was observed for all the model systems since the flow behavior index $(n)$ ranges from $1<n<3$. This means that a slight load may disturb the equilibrium stability of the packaged beef to cause an increase in the shear stress with an increase in the deformation in the direction of the percent rate of shear. Also, a better estimation of the deformation consistency, $k$ was obtained using the Tiu-Boger theory for the A. Foil at cooling temperature, whereas the parameter was better estimated using the Herschel-Bulkley theory for the LD at freezing temperature. All the models are statically significant and valid with an MSE $<5 \%$ and a high coefficient of determination ( $\mathrm{R}^{2}$ and $\mathrm{R}^{2}$ adj $>80 \%$ ). This suggests the potential of the models for predicting the rheological properties of beef, especially during industrial large-scale production.

\section{CONFLICTS OF INTEREST}

No conflict of interest was declared by the author.

\section{REFERENCES}

[1] Akoğlu, I.T., Bıyıkl1, M., Akoğlu, A., Kurhan, Ş., "Determination of the quality and shelf life of sous vide cooked turkey cutlet stored at 4 and $12^{\circ} \mathrm{C}^{\prime}$, Brazilian Journal of Poultry Science, 20(1): 1-8, (2018).

[2] Bhattacharya, M., Hanna, M.A., Mandigo, R.W., "Effect of frozen storage conditions on yields, shear strength and color of ground beef patties", Journal of food Science, 53(3), 696-700, (1988).

[3] Poore, J., Nemecek, T., "Reducing food's environmental impacts through producers and consumers", Science, 363(4): 939-939, (2019).

[4] Lepetit, J., Culioli, J., “Mechanical properties of meat”, Meat science, 36(1-2): 203-237, (1994).

[5] James, A.E., Williams, D.J.A., Williams, P.R., "Direct measurement of static yield properties of cohesive suspensions", Rheologica Acta, 26(5): 437-446, (1987). 
[6] Zhu, L., Sun, N., Papadopoulos, K., De Kee, D., "A slotted plate device for measuring static yield stress", Journal of Rheology, 45(5): 1105-1122, (2001).

[7] Uhlherr, P.H.T., Guo, J., Tiu, C., Zhang, X.M., Zhou, J.Q., Fang, T.N., “The shear-induced solid-liquid transition in yield stress materials with chemically different structures", Journal of Non-Newtonian Fluid Mechanics, 125(2-3): 101-119, (2005).

[8] Nguyen, Q.D., Akroyd, T., De Kee, D.C., Zhu, L., "Yield stress measurements in suspensions: an interlaboratory study", Korea-Australia Rheology Journal, 18(1): 15-24, (2006).

[9] Barbosa, C., Diogo, F., Alves, M.R., "Fitting mathematical models to describe the rheological behaviour of chocolate pastes", In AIP Conference Proceedings, 1738(1): 370-376, (2016).

[10] Dzuy, N.Q., Boger, D.V., "Yield stress measurement for concentrated suspensions", Journal of Rheology, 27(4): 321-349, (1983).

[11] Dzuy, N.Q., Boger, D.V., "Direct yield stress measurement with the vane method", Journal of Rheology, 29(3): 335-347, (1985).

[12] Chapwanya, M., Misra, N.N., "A mathematical model of meat cooking based on polymer-solvent analogy", Applied Mathematical Modelling, 39(14): 4033-4043, (2015).

[13] Nguyen, Q.D., Boger, D.V., "Measuring the flow properties of yield stress fluids", Annual Review of Fluid Mechanics, 24(1): 47-88, (1992).

[14] Fadeyibi, A., Osunde, Z.D., Yisa, M.G., "Prediction of Some Physical Attributes of Cassava StarchZinc Nanocomposite Film for Food-Packaging Applications", Journal of Packaging Technology and Research, 3(1): 35-41, (2019).

[15] Karaman, S., Yilmaz, M.T., Kayacier, A., Dogan, M., and Yetim, H., "Steady shear rheological characteristics of model system meat emulsions: Power law and exponential type models to describe effect of corn oil concentration", Journal of Food Science and Technology, 52(6): 3851-3858, (2015).

[16] Rao, M.A., Tattiyakul, J., "Granule size and rheological behavior of heated tapioca starch dispersions", Carbohydrate Polymers, 38(2): 123-132, (1999).

[17] Saraiva, C., Fontes, M. D. C., Patarata, L., Martins, C., Cadavez, V., Gonzales-Barron, U., "Modelling the kinetics of Listeria monocytogenes in refrigerated fresh beef under different packaging atmospheres", LWT-Food Science and Technology, 66: 664-671, (2016).

[18] Jakobsson, B., Bengtsson, N., "Freezing of cooked meat: Influence of freezing rate and reconstitution method on quality and yield", Journal of Food Science, 39(3): 615-619, (1974).

[19] Law, H.M., Yang, S.P., Mullıns, A.M., Fielder, M.M., "Effect of Storage and Cooking on Qualities of Loin and Top-Wound Steaks", Journal of Food Science, 32(6): 637-641, (1967).

[20] Smith, G.C., Carpenter, Z.L., King, G.T., "Considerations for beef tenderness evaluations", Journal of Food Science, 34(6): 612-618, (1969). 
[21] Bouton, P.E., Harris, P.V., Shorthose, W.R., "Changes in shear parameters of meat associated with structural changes produced by aging, cooking and myofibrillar contraction”, Journal of Food Science, 40(6): 1122-1126, (1975).

[22] Locker, R.H. "A new theory of tenderness in meat, based on gap filaments", Reciprocal Meat Conference Proceedings, 35: 1-10, (1982).

[23] Chen, C.R., Marcotte, M., Taherian, A., "Kinetic modeling of texture properties of Bologna sausage under cooking conditions", International Journal of Food Properties, 12(1): 252-260, (2009).

[24] Constenla, D.T., Lozano, J.E., Crapiste, G.H., "Thermophysical properties of clarified apple juice as a function of concentration and temperature", Journal of Food Science, 54(3): 663-668, (1989).

[25] Hassan, B.H., Hobani, A.I., "Flow properties of Roselle (Hibiscus sabdariffa L.) extract", Journal of Food Engineering, 35(4): 459-470, (1998).

[26] Onwude, D.I., Hashim, N., Janius, R.B., Nawi, N.M., Abdan, K., "Modeling the Thin-Layer Drying of Fruits and Vegetables: A Review", Comprehensive Review in Food Science Food Safety, 15(3): 599-618, (2016). 